Proceedings

\title{
Eocene North American Testudinidae and Geoemydidae (Reptilia, Testudines): A Re-Evaluation of Their Alpha Taxonomy, Ecology, and Origin +
}

\author{
Asher J. Lichtig ${ }^{1, *}$, Steven E. Jasinski ${ }^{2,3}$ and Spencer G. Lucas ${ }^{1}$ \\ 1 New Mexico Museum of Natural History, 1801 Mountain Road NW, Albuquerque, NM 87104, USA; \\ spencer.lucas@state.nm.us \\ 2 Department of Earth and Environmental Science, University of Pennsylvania, Philadelphia, PA 19104-6316, \\ USA; sejasinski@gmail.com \\ 3 Section of Paleontology and Geology, State Museum of Pennsylvania, Harrisburg, PA 17120-0024, USA \\ * Correspondence: ajlichtig@gmail.com \\ + Presented at the 2nd International Electronic Conference on Geosciences, 8-15 June 2019; Available online: \\ https://iecg2019.sciforum.net/.
}

Published: 4 June 2019

\begin{abstract}
We describe new material, including juvenile specimens, of Hadrianus corsoni, Hadrianus majusculus, Echmatemys haydeni, and Echmatemys naomi. Testudinidae evolved in North America from one of the geoemydid-like forms in the genus Echmatemys, which have their lowest stratigraphic occurrence in the earliest Wasatchian North American land mammal "age" (early Eocene, Ypresian).
\end{abstract}

Keywords: turtle; tortoise; Eocene; Echmatemys; Hadrianus

\section{Introduction}

The genus Echmatemys was originally created by Hay [1] for Echmatemys septaria from the early middle Eocene (Bridgerian North American land mammal "age"; NALMA) of Wyoming. Over the next two decades, this genus rapidly grew to include all Eocene non-testudinid, testudinoid turtles in North America, with approximately 20 named species [2]. These were inferred to be immigrants from Asia, as the stem members of the Testudinoidea are entirely from Asia [3]. Here, we describe three new specimens of Echmatemys and Hadrianus of unusual completeness that lead us to explore the implications of this taxon for the early ecology and origin of tortoises.

\section{Results}

\subsection{Testudinidae}

Remarks: Prominent costal wedging is a trait often associated with Testudinidae. We use this in the same way Hay did [2]; it is associated with the proximal widening of costals 3 and 5 and the proximal narrowing of costals 2,4 , and 6 .

\subsection{Hadrianus corsoni}

New material: Reconstruction of a hatchling turtle skeleton identified as Hadrianus corsoni (FOBU 14015, Figure 1) is nearly complete, including the skull, carapace, posterior two-thirds of the plastron, and incomplete limbs. 
Skull: The skull (Figure 1) is $13 \mathrm{~mm}$ long and $9.7 \mathrm{~mm}$ wide. The frontal forms the posterior half of the dorsal margin of the orbit. The frontals have a distinct anteromedial projection between the prefrontals. The orbits are anteriorly placed just behind the anterior tip of the snout. The parietals are large, forming most of the posterior portion of the skull roof. The postorbital is large and expanded laterally, is triangular, and is sutured to the parietal and frontal. It forms the entire posterior margin of the orbit. The prefrontals are roughly rectangular, forming the dorsal anterior portion of the orbital margin. The maxilla forms much of the lateral margin of the nasal passage and the floor of the orbit. The squamosal and quadrate suture is about halfway between the posterior margin of the postorbital and the posterior extremity of the supraoccipital. The articular of each side of the mandible is below the skull, about $3 \mathrm{~mm}$ lateral to either side of the supraoccipital.

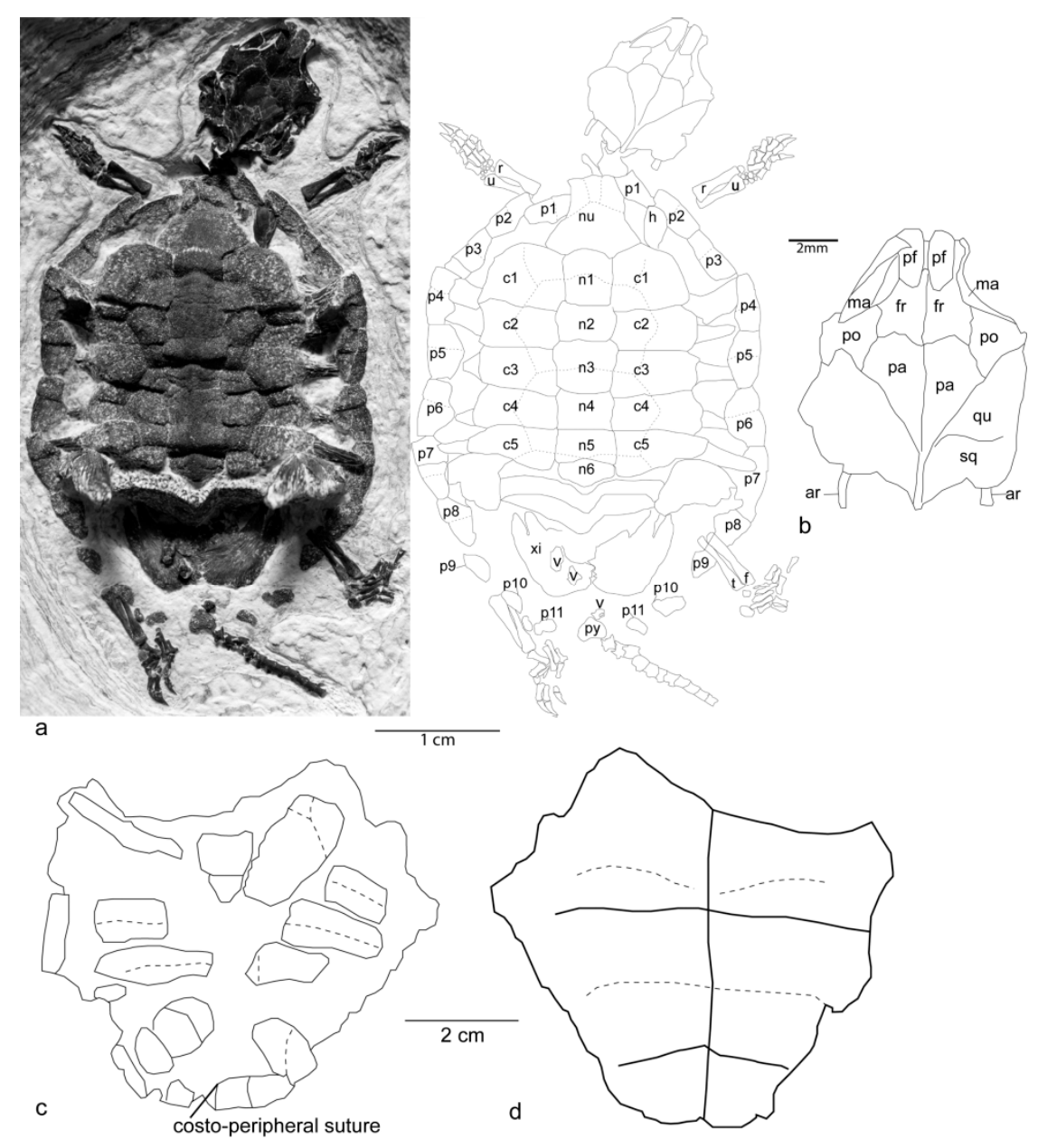

Figure 1. An articulated juvenile Hadrianus corsoni skeleton, FOBU 14015: (a) dorsal view (left side) and line drawing of the same (right side); (b) line drawing showing sutures of the dorsal view of the skull. (c,d) Hadrianus majusculus, juvenile, incomplete carapace and plastron, UCB 76816, with line drawing of (c) dorsal and (d) ventral views. Abbreviations: ar, articular; c, costal; f, fibula; fr, frontal; $\mathrm{h}$, humerus; ma, maxilla; $\mathrm{n}$, neural; nu, nuchal; $\mathrm{p}$, peripheral; pa, parietal; pf, prefrontal; po, postorbital; py, pygal; qu, quadrate; r, radius; sq, squamosal; t, tibia; $u$, ulna; xi, xiphiplastron.

Carapace: The carapace (Figure 1) is $40 \mathrm{~mm}$ long and $31.3 \mathrm{~mm}$ wide. It has the distinct medial ridge typical of many juvenile testudinoids. The posterior three peripherals and the pygal are poorly ossified, and do not contact each other. Costal wedging is present, and the neurals and proximal portions of the costals show the typical striated surface sculpture of Hadrianus. The sulci are deeply incised into the carapace. The nuchal is well-developed, contacting neural 1, both first peripherals, and both first costals. Neural 1 is rectangular, $6.3 \mathrm{~mm}$ long and $5.8 \mathrm{~mm}$ wide, contacts costal 1 , and is crossed by the vertebral 1-2 sulcus. Neural 2 is hexagonal, $2.5 \mathrm{~mm}$ long and $8.1 \mathrm{~mm}$ wide, contacts costals 1 and 2, and is not crossed by sulci. Neural 3 is hexagonal, with short sides paralleling the 
midline near the crossing of the vertebral $2-3$ sulcus. It is $5 \mathrm{~mm}$ long and $4.4 \mathrm{~mm}$ wide. Neural 4 is hexagonal, with extremely short anterior lateral sides, and is $5 \mathrm{~mm}$ long and $5 \mathrm{~mm}$ wide. It lacks any crossing sulcus and contacts costals 3,4 , and 5 , although the contact with costal 5 is small. Neural 5 is rectangular, and very slightly elongated anteriorly and posteriorly along the midline. It is crossed by the vertebral 3-4 sulcus. All three vertebral-vertebral sulci bow anteriorly as they cross the midline, creating a slight "omega" shape. Neural 6 is tilted nearly vertical, so some of its features are obscured; however, it appears as rectangular, with no division of the lateral sides. The neural formula up to neural 6 is $4-6 \mathrm{~A}-6 \mathrm{~A}-6 \mathrm{~A}-4-4$. The lateral margin of the carapace is slightly concave between peripherals 5 and 6 . The greatest width is at the peripheral 6-7 suture.

Plastron: Both the hyoplastron-hypoplastron and the hypoplastron-xiphiplastron fontanelles are open. The midline suture is loose and unsutured in some areas. The inguinal buttress is well ossified between the distal third of costals 5 and 6, and was pushed through the carapace taphonomically.

Limbs: The forelimbs are nearly complete, but the humerus is partly covered by the anterior peripherals. Both ulnae are $4.4 \mathrm{~mm}$ long, and the hands are $6 \mathrm{~mm}$ long. The distal phalanges have a small flexor tubercle. The phalangeal formula is 0-3-3-3-3. The left hind limb is relatively complete, including a $5 \mathrm{~mm}$ long tibia and a $6 \mathrm{~mm}$ long pes. The distal phalanges of the pes lack a well-defined flexor tubercle. Neither pes preserves full digits 1 or 2 . The phalangeal formula is ?-?-3-3-3.

\subsection{Hadrianus majusculus}

New material: UCB 76816; incomplete carapace and plastron, missing the anterior and posterior ends of the plastron, as well as most peripherals; the nuchal; and the pygal. Distribution: Wasatchian (Wa-5) of the Willwood Formation of Wyoming, USA.

Description: An incomplete shell (Figure 1) identified as Hadrianus majusculus based on: (1) lack of costal wedging; (2) posteriorly concave pectoral-abdominal sulcus; and (3) narrow base of anterior lobe of plastron relative to base of posterior lobe. The hyoplastron measures $20 \mathrm{~mm}$ long and the hypoplastron is $21 \mathrm{~mm}$ long. The hyoplastron has four scute annuli, indicating an individual approximately 4 years old [4].

\subsection{Echmatemys lativertebralis (Family Unconfirmed)}

Distribution: Early Eocene (Wasatchian), San Jose Formation, New Mexico; Wasatch Formation, Wyoming; DeBeque Formation, Colorado.

Remarks: Echmatemys lativertebralis is more distinct from the other species of Echmatemys than they are from each other. E. lativertebralis averages $250 \mathrm{~mm}$ carapace length. Vlachos [5] recognizes Echmatemys cibollensis as distinct from E. lativertebralis, but this is only based on the extent of the gulars overlapping the entoplastron, which varies in all testudinoid species.

\subsection{Echmatemys haydeni}

Referred specimen: An articulated skeleton from the Green River Formation (TMP 2008.00.14, Figure 2) includes the first known skull of Echmatemys haydeni. Identification is based on the long contact of marginal 1 and pleural 1, as well as the overlap of the posterior sulcus of vertebral 5 over the pygal. The large medial extent of the inguinal buttresses due to the costals separating them nearly to the costal-neural sutures is unusual. 

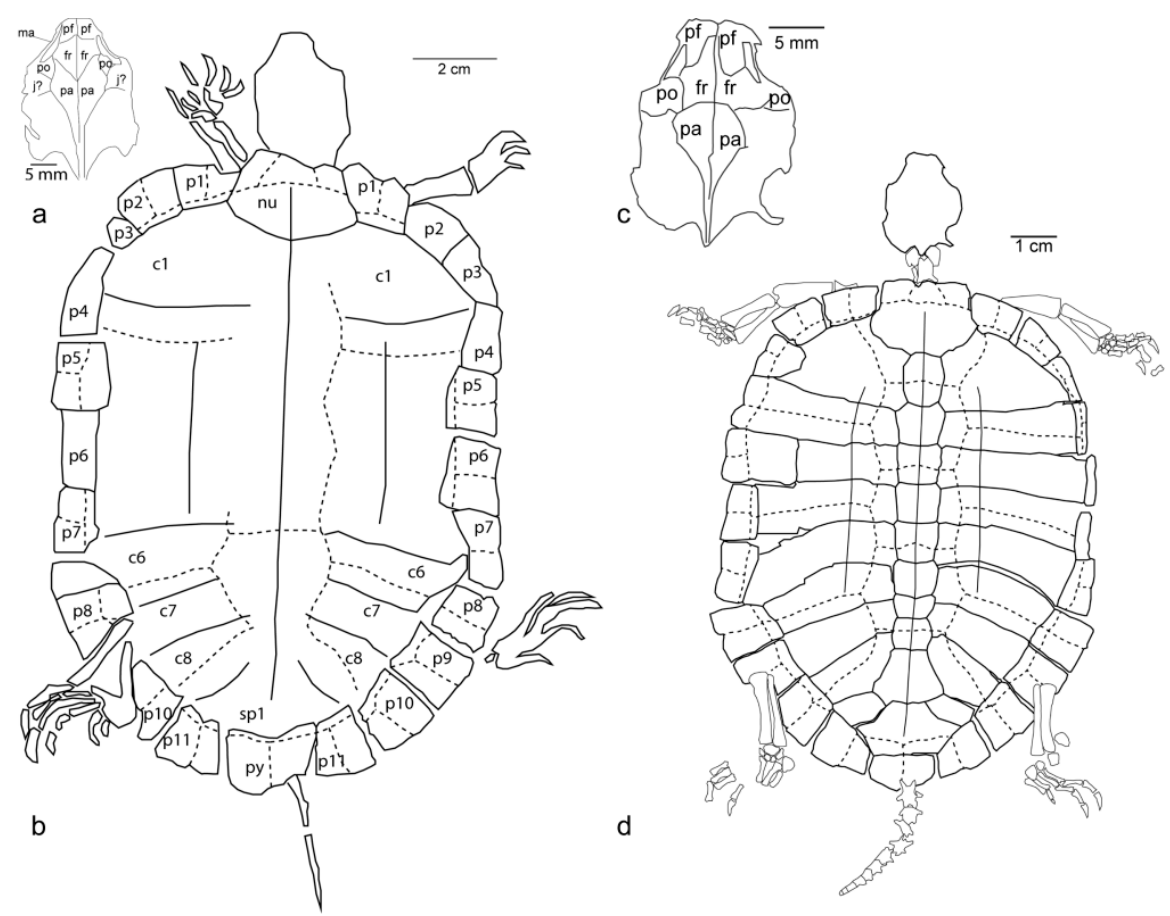

Figure 2. (a,b) Echmatemys haydeni articulated skeleton, TMP 2008.00.14. Line drawing of dorsal aspect of skull (a); line drawing of entire specimen (b). (c,d) Echmatemys naomi articulated skeleton, FOBU 14014. (c) Line drawing of skull and (d) line drawing of specimen. Abbreviations: c, costal; fr, frontal; j?, jugal (unconfirmed); ma, maxilla; nu, nuchal; p, peripheral; pa, parietal; pf, prefrontal; po, postorbital; py, pygal; spy, suprapygal.

Description: The skull is $31 \mathrm{~mm}$ long, $21 \mathrm{~mm}$ wide, and dorsoventrally compressed, with most elements below the skull table obscured. The postorbitals are reduced, with another bone (possibly jugal) forming much of the ventral posterior margin of the orbit. The anterior process of the frontal is small relative to that of Echmatemys naomi. The frontals lie rostrally, mainly medial to the orbits, and extend caudally slightly beyond the caudal edge of the orbital rim. The frontals in this specimen project posteromedially between the parietals, allowing the parietals to project anterolaterally toward the orbital rim, resulting in reduced postorbitals. This also makes the parietals prominent, extending between the orbits beyond their posterior rim, distinctly farther than in Hadrianus corsoni and E. naomi. The carapace is complete, $142 \mathrm{~mm}$ long, with the normal complement of scutes and bones seen in Echmatemys [2]. Five or six growth annuli are present on costal 1, suggesting this individual was at least five years old when it died [4].

\subsection{Echmatemys naomi}

Referred specimen: A nearly complete skeleton of Echmatemys naomi from the Green River Formation (FOBU 14014, Figure 2). The identification is based on the lack of overlap of the nuchal by the pleurals, neural 1 being much longer than is it wide, the presence of the vertebral $4-5$ sulcus over the last neural, and the wide suprapygal.

Description: FOBU 14014 has a carapace length of $110 \mathrm{~mm}$. The first costal has four growth lines, suggesting this turtle's age at death was $\sim 4$ years [4]. The carapace is similar to other Echmatemys naomi specimens [2]. The skull is more robust (22.7 $\mathrm{mm}$ long, $16 \mathrm{~mm}$ wide) than $E$. haydeni, with more pronounced prefrontals. The frontals have a larger anteromedial process along the midline. The right prefrontal is dislocated, covering part of the anterior process of the frontals. The postorbital excludes the jugal from the dorsal margin of the orbit. The parietals form a posteriorly concave suture with the frontals, rather than anteriorly concave with a posteromedial projection of the frontals between them. 


\section{Discussion}

Following the end-Cretaceous mass extinction, no terrestrial families of turtles survived in the northern continents [6]. This left terrestrial turtle niches open, possibly until the Eocene. Basal testudinids have long been assumed to have an ecology similar to extant testudinids. This assumption is challenged by Manouria emys, the most basal extant testudinid, which has a distinct ecology [7], including a unique mode of food apprehension, breeding behavior, and a greater willingness to attempt subaqueous food capture. The histology of Hadrianus is that of a semi-aquatic to aquatic turtle [8]. It is near the base of a long stem leading to crown testudinids, so we need not assume they were similar to extant or even fossil crown testudinids in their ecology.

The oldest tortoises are stem-Testudinidae from the early Eocene of North America. The first record of these tortoises is Hadrianus majusculus [9] from the late Wasatchian (Wa-5) of North America (the oldest reported pantestudinid). Purported stem-Testudinidae and testudinids have been reported from the Eocene of Asia. A recent revision of Anhuichelys [10] concluded that it is a stem-testudinid, rather than an emydid, as previously proposed [11]. However, the phylogenetic analysis [10] is suspect, given that if either of the two characters are subtracted, the analysis finds a sister group relationship of Anhuichelys with Platysternon [9]. This sister clade was found to be sister to both basal testudinoids included in the analysis (Lindholemys and Mongolemys). This agrees with the original placement [11]. Purported stem-Testudinidae mentioned from Mongolia [12] have never been published. These come from the "Naran Bulak Formation of Khaichin Ula IV and the Tsagan Khushu localities" (Igor Danilov pers. com., 2016). Tsagan Khushu is of late Paleocene to early Eocene age in the Naran Bulak Svita, whereas Khaichin Ula IV is of middle Eocene age in the Khaychin Svita [13].

Perez-Garcia et al. [14] revised Europe's oldest tortoises, naming Fontainichelon for the species "Achilemys cassouleti" [15]. They suggested the specimen is early Eocene (MP 8-9), roughly equivalent to the late Wasatchian NALMA. This is contrary to the original description, which placed it in MP 10, or approximately equivalent to the Bridgerian NALMA. There is some confusion between the sites in that region of France-the application of the age of the "La Borie" locality to these specimens, which are from a different locality ("Saint-Papoul"), is not justified [16]. Thus, Fontainichelon is younger than North American Hadrianus.

Fontainichelon is also not the most basal testudinid, an assessment based on "the presence of narrower and longer gular scutes and a "wavy" humero-pectoral sulcus, with the medial part being "convex anteriorly" [14]. Fontainichelon and Hadrianus have similar-sized gular scutes, each occupying approximately one-third of the length of the midline. The "wavy" sulcus is present in a wide variety of taxa in the Emydidae, Geoemydidae, and Testudinidae, and encompasses a number of distinct morphologies. The closest comparison is Rhinoclemmys pulcherima, a basal geoemydid. While this character is distinct in mature individuals, it is completely absent in a three-month-old hatchling of R. pulcherima, which has a transverse humeral pectoral sulcus (which develops by 15 months).

Hutchison [17] proposed that Testudinidae entered North America from Asia during the second thermal maximum of the Eocene ( 52 Ma). Hutchison [17] and Holroyd et al. [18] identify three important events: (1) Echmatemys sensu lato appearing in North America by Wa-0; (2) Baptemys appearing, likely an immigrant from south of Texas, at Wa-5; and (3) at this same horizon in the Willwood Formation, Testudinidae make an abrupt first appearance. Instead, we conclude that Echmatemys [2] is a combination of at least three groups that entered North America at about the Paleocene-Eocene thermal maximum and emigrated from North America to Europe and Asia by the earliest Bridgerian. The oldest and most basal tortoises are from the western United States. 


\begin{tabular}{cc}
\hline $\begin{array}{c}\text { Institutional } \\
\text { Abbreviation }\end{array}$ & Location \\
\hline FOBU & Fossil Butte National Monument, Kemmerer, Wyoming, USA \\
\hline TMP & Royal Tyrrell Museum of Palaeontology, Drumheller, Alberta, Canada \\
\hline UCB & University of Colorado Museum of Natural History, Boulder, Colorado, USA \\
\hline
\end{tabular}

Author Contributions: Conceptualization, formal analysis, investigation, writing-original draft preparation, writing - review and editing, visualization: A.J.L., S.E.J., and S.G.L.

Funding: This research received no external funding

Acknowledgments: We thank Arvid Aase and the staff of FOBU for providing access to specimens. We also thank Tonia Culver and the UCB for access to their collections.

Conflicts of Interest: The authors declare no conflict of interest.

\section{References}

1. Hay, O.P. Descriptions of two new genera (Echmatemys and Xenochelys) and two new species (Xenochelys formosa and Terrapene putnami) of fossil turtles. Bull. American Mus. Nat. Hist. 1906, 22, 27-31.

2. Hay, O.P. The Fossil Turtles of North America; Carnegie Institute of Washington Publications: Washington DC, USA, 1908; Volume 75, 568p.

3. Cadena, E.A.; Ksepka, D.T.; Norell, M.A. New material of Mongolemys elegans Khosatzky and Mlynarski, 1971 (Testudines: Lindholmemydidae), from the Late Cretaceous of Mongolia with comments on bone histology and phylogeny. Am. Museum Novitates 2013, 3766, 1-29.

4. Zug, G.R. Age determination in turtles: Society for the Study of Amphibians and Reptiles. Herpetol. Circ. 1991, 20, 1-28.

5. Vlachos, E., A Review of the Fossil Record of North American Turtles of the Clade Pan-Testudinoidea. Bull. Peabody Mus. Nat. Hist. 2018, 59, 3-94.

6. Lichtig, A.J.; Lucas, S.G., Cretaceous nonmarine turtle biostratigraphy and evolutionary events: New Mexico Mus. Nat. Hist.Sci. Bull. 2016, 71, 185-194.

7. Natchv, N.; Tzankov, N.; Werneburb, I.; Heiss, E. Feeding behavior in a 'basal' tortoise provides insights on the transitional feeding mode at the dawn of modern land turtle evolution. PeerJ 2015, 3, e1172. doi:10.7717/peerj.1172.

8. Scheyer, T.M.; Sander, P.M. Shell bone histology indicates terrestrial palaeoecology of basal turtles. Proc. R. Soc. Lond. B Biol. Sci. 2007, 274, 1885-1893.

9. Cope, E.D. Report upon vertebrate fossils discovered in New Mexico, with descriptions of new species: U.S. War Department, Chief Engineer Annual Report, 1874, 43rd Congress, 2nd Session, House Executive Document 1, pt. 2; v. 2, pt. 2, Appendix FF, pp. 589-606.

10. Tong, H.; Li, L.; Li, D.S.; Chen, L.M.; Li, T.; Yu, S.H.;Yu, G.S.; Cheng, X.Q.; Claude, J. A revision of Anhuichelys Yeh, 1979, the earliest known stem Testudinidae (Testudines: Cryptodira) from the Paleocene of China. Vertebrata PalAsiatica 2016, 54, 156-179.

11. Yeh, H.K. Paleocene turtles from Anhui. Vertebr. PalAsiat. 1979, 17, 49-56.

12. Holroyd, P.A.; Parham, J.F. The antiquity of African tortoises: J. Vertebr. Paleontol. 2003, 23, 688-690.

13. Russell, D.E.; Zhai, R.-J. The Paleogene of Asia: Mammals and stratigraphy. Mem. du Mus. Natl. d'hist. Nat. 1987, 52, 488.

14. Perez-Garcia, A.; Ortega, F.; Fuentes, E.J. Taxonomy, systematics, and diversity of the European oldest testudinids. Zool. J. Linn. Soc. 2016, 177, 648-675.

15. Claude, J.; Tong, H. Early Eocene testudinoid turtles from Saint-Papoul, France, with comments on the early evolution of modern Testudinoidea. Oryctos 2004, 5, 3-45.

16. Danilo, L.; Remy, J.A.; Vianey-Liaud, M.; Marandat, B.; Sudre, J.; Lihoreau, F. A new Eocene locality in southern France sheds light on the basal radiation of Palaeotheriidae (Mammalia, Perissodactyla, Equoidea). J. Verteb. Paleontol. 2013, 33, 195-215, doi:10.1080/02724634.2012.711404. 
17. Hutchison, J.H. Turtle stratigraphy of the Willwood Formation, Wyoming: Preliminary results: University of Michigan, Museum of Paleontology, Papers on Paleontology. J. Vertebr. Paleontol. 1980, 24, 115-118.

18. Holroyd, P.A.; Hutchison, J.H.; Strait, S.G. Turtle diversity and abundance through the lower Eocene Willwood Formation of the southern Bighorn Basin. Univ. Mich. Pap. Paleontol. 2001, 33, 97-107.

(C) 2019 by the authors. Licensee MDPI, Basel, Switzerland. This article is an open access article distributed under the terms and conditions of the Creative Commons Attribution (CC BY) license (http://creativecommons.org/licenses/by/4.0/). 